\title{
Placenta Accreta - Diagnosis and Management
}

\author{
A.S. Dhillon ${ }^{1}$, Mansi², Girisha Mehta $^{3}$, Gagandeep Kaur ${ }^{4}$ Angela Yadav ${ }^{5}$ \\ 1, 2,3,4,5 Department of Obstetrics and Gynaecology, Maharishi Markandeshwar \\ Institute of Medical Sciences and Research, Mullana, Haryana, India.
}

\section{INTRODUCTION}

Placenta accreta is a potential grievous obstetric condition that calls for a multidisciplinary timely management. Placenta accreta refers to placenta that is firmly adherent to the myometrium. ${ }^{1}$ Three types of adherent placental attachments are, placenta accreta (the uterine decidua is absent and the chronic villi attaches to the myometrium directly), placenta increta (the chronic villi invades into the myometrium), and placenta percreta (the villi penetrate the myometrium up to the serosal layer). ${ }^{2}$

The incidence of placenta accreta has increased ten-fold in the past 50 years. $^{3}$ It can lead to excessive bleeding, haemorrhagic and neurogenic shock, sepsis, uterine inversion, or need for hysterectomy. ${ }^{4}$

Previous obstetrics interventions like caesarean deliveries are the largest risk factor for the placenta accreta, or previous dilatation and curettage or previous manual removal of placenta. Increasing maternal age and parity, as well as other uterine surgeries also have increased risks. When placenta accrete is suspected, a multidisciplinary team with expertise should be there to take care of such cases. Although ultrasound and magnetic resonance image (MRI) may or may not indicate clearly an invasive placenta, the final diagnosis is made intra-operatively and is supported by histopathological examination. ${ }^{4}$

Placenta accreta is associated with high morbidity and mortality of the mother and the foetus and has high demands on health resources. Antepartum haemorrhage may occur in such cases if there is associated placenta previa. MRI is the best modality for diagnosis when there is suspicion of placenta accreta clinically.

\section{PRESENTATION OF CASE}

A 25 years old registered patient G2P1L1 with gestational age 29 weeks +4 days with previous full-term vaginal delivery presented in emergency with leaking per vaginum since 2 days. Her antenatal period was uneventful up till now. She was calm, conscious and well oriented to time, place and person with her PR - 94 / min, regular and good volume, $\mathrm{BP}$ - $120 / 80 \mathrm{mmHg}$, Temp - $98.4^{\circ} \mathrm{F}, \mathrm{SpO}_{2}$ - $98 \%$ at room air. Her chest was clear and bilateral air entry was equal. Normal heart sounds were present and no murmur was heard. On abdominal examination, the uterus was globular and soft. Fundal height was 26 wks.

Uterus was relaxed and non-tender and presentation of fetus was cephalic. Fetal heart was 136 beats per minute. On speculum examination frank leaking was seen, liquor was clear and odorless there was no evidence of bleeding / spotting. ${ }^{5}$
Corresponding Author:

Dr. Girisha Mehta,

Department of MMU Mullana Org,

Maharishi Markandeshwar Institute of

Medical Sciences and Research, Mullana,

Haryana, India.

E-mail: drgirishamehta2816@gmail.com

DOI: $10.14260 / j e m d s / 2020 / 674$

How to Cite This Article:

Dhillon AS, Mansi, Mehta G, et al. Placenta accreta - diagnosis and management. J Evolution Med Dent Sci 2020;9(41):30733074, DOI: 10.14260/jemds/2020/674

Submission 07-07-2020,

Peer Review 04-09-2020,

Acceptance 10-09-2020,

Published 12-10-2020.

Copyright (C) 2020 JEMDS. This is an open access article distributed under Creative Commons Attribution License [Attribution 4.0 International (CC BY 4.0)] 
Patient was admitted and USG was done, which showed fetal parameters of 29 wks. +6 days, placenta was anterior with small collection of $3 * 0.9 \mathrm{~cm}, \mathrm{AFI}-3-4$, BPP - 6 / 8, and doppler was normal. Her investigations were sent, steroids ( Hb - 8.7 gm \%, TLC - $11.3 * 1000$, CRP - 0.97, HVS showed polymicrobial growth) and antibiotic cover was given.

Patient was kept on expectant management. Strict monitoring of maternal and fetal parameters were done. After 7 days patient went into labour spontaneously and delivered a female child of $1.367 \mathrm{~kg}$ who cried immediately after birth but was kept in NICU facility for further evaluation. Her delivery was uneventful until the placenta was found incomplete and active management of $3^{\text {rd }}$ stage of labour was done. Patient was monitored very closely, and tab misoprostol $600 \mathrm{mcg}$ was kept per rectally and inj. oxytocin 20 IU was given I / v after delivery and additional 10 IU were given to accelerate the expulsion of retained placenta.

Patient was kept under close watch for PPH. Patient voided urine $1 \mathrm{hr}$. post-delivery and uterus was well retracted. Patient was kept under observation and USG was done which showed vascular RPOC's $(7 * 3 \mathrm{~cm})$ with inner myometrium adhered along posterior wall s / o placenta accreta. Patient was explained about the grave risks. Her repeat investigations were sent (in which $\mathrm{Hb}-6.5$ gm \%) hence 2 units of PRBC's were transfused and more and more blood and FFP's were arranged and kept ready. And decision was taken to medically manage the patient by tablet mifepristone $200 \mathrm{mg}$ TDS was given.

On a serial USG, myometrial invasion was seen to be reduced. However, the RPOC's were not expelled, PAC was done and the patient was prepared for OT. She underwent USG guided dilatation and evacuation. Adherent placental pieces were evacuated by ovum forceps and blood loss was approximately $600 \mathrm{ml} .1$ unit PRBC was given intraoperatively. RPOC's were sent for histopathological examination and patient was shifted in gynae ICU for observation. Repeat USG was done which showed normal study and patient was discharged on day $3^{\text {rd }}$ of D \& C under stable condition and was called for follow up after a week.

\section{DISCUSSION}

The incidence of placenta accrete has increased 10 fold in the past 50 years. Various complications like endometritis, fever, admission to intensive care and risk for massive haemorrhage necessitating blood transfusion can also occur.
Mifepristone is a progesterone receptor inhibitor which in turn increases uterine contractility that leads to cervical dilatation and also sensitises the uterine myometrium to the effects of misoprostol.

Use of mifepristone has not been established yet in the treatment of placenta accrete although it was useful in the above mentioned case. And as placenta accrete cannot always be diagnosed in the antepartum or during labour, more commonly when there are no high risk factors present, so in that case, adequate measures cannot always be taken. Even though hysterectomy remains the most common treatment modality drugs like misoprostol, mifepristone (as in our case) and methotrexate have also been successfully used preventing the need for hysterectomy.

\section{CONCLUSIONS}

Placenta accreta is a life threatening condition for both mother and baby. Multiple treatment modalities, either alone or in combination can be used for such cases. This case report highlights the possibility of using drugs like mifepristone in the management of placenta accrete as a safe alternative to other methods available.

Financial or Other Competing Interests: None.

\section{REFERENCES}

[1] Stocker JT, Dehner LP. Pediatric pathology. Vol. 1. $2^{\text {nd }}$ edn. USA: Lippincott Williams and Wilkin 2001.

[2] Shnider SM, Levinson G. Anesthesia for obstetrics. $3^{\text {rd }}$ edn. USA: Williams and Wilkins 1993.

[3] Committee on Obstetric Practice. ACOG committee opinion. Placenta accreta. Number 266, January 2002. American College of Obstetricians and Gynecologists. Int J Gynaecol Obstet 2002;77(1):77-8.

[4] Bretelle F, Courbiere B, Mazouni C, et al. Management of placenta accreta: morbidity and outcome. Eur J Obstet Gynecol Repord Biol 2007;133(1):34-9.

[5] Morgan M, Atalla R. Mifepristone and misoprostol for the management of placenta accreta - a new alternative approach. BJOG 2009;116(7):1002-3. 